\title{
THE ROLE OF LOCAL GOVERNMENTS IN MANAGING EU STRUCTURAL FUNDS FOR ENTREPRENEURIAL DEVELOPMENT
}

\author{
https://doi.org/10.47743/jopafl-2021-20-08
}

\author{
Fabio De MATTEIS \\ Ionian Department of Law, Economics and Environment, University of Bari \\ Bari, Italy \\ fabio.dematteis@uniba.it
}

Fabrizio STRIANI

Department of Innovation Engineering, University of Salento

Salento, Italy

Piervito BIANCHI

Department of Economics, University of Foggia

Foggia, Italy

\begin{abstract}
The EU provides financial support to promote economic development, but the results of development policies are affected by different of actors, among which public administration is particularly important. The goal of this paper is to investigate both the role of local authorities in the management of European structural funds intended for entrepreneurial development, and the role of other users of these funds. Applying the GLS method on a sample composed by the 116 Italian provincial capitals and considering the period 2014-2017 (n. 464 observations), our findings show that local governments produced higher positive impact, than other actors, in managing EU structural funds for local entrepreneurial development. Finally, we suggest policy making and managerial implications arising from the research findings.

Keywords: public management; local government; EU structural funds; entrepreneurial development
\end{abstract}

\section{Introduction}

The EU provides financial support to promote economic development and social inclusion through the so called structural funds (Zerbinati, 2012). They are aimed at increasing long-term growth facing economic crisis in order to face and reduce its negative effects. Therefore, structural funds are particularly relevant in times like the one the world is going through, characterized by a pandemic that creates profound health and economic difficulties (Arbolino and Di Cairo, 2021). European structural funds can be a supporting element for economic development (Murzyn, 2020) related to both profit and non-profit organizations (Potluka et al., 2017).

Specifically, in this paper the entrepreneurial level (in terms of difference between registered companies and deceased companies in a fiscal year) is considered as an indicator of economic development (Namise et al. 2019): in effect, it is an important source of the gross domestic product that is widely used as an indicator of economic development. The 
hypothetical success or failure of development policies is affected by a variety of supporting factors that are interconnected and involve a plurality of actors (Casula, 2020). Among these, it must be considered that the theme of economic development includes the role of a key player in programming and implementing economic development policies represented by public administrations (Calcagnini and Perugini, 2019). This is a particularly topical theme considering the Sustainable Development Goal n. 8 of the U.N. 2030 Agenda. In effect, it states: "Promote development-oriented policies that support productive activities, decent job creation, entrepreneurship, creativity and innovation, and encourage the formalization and growth of micro-, small- and medium-sized enterprises, including through access to financial services."

From these aspects the object of the paper arises. It is to investigate the role of local governments in managing EU structural funds addressed to economic development and to compare it to the role of other players. In order to achieve the stated objective, the article is structured as follows. Section 2 analyzes literature contributions on the relevance of the European structural funds for the economic development highlighting the role played by public sector organizations in implementing economic development policies. This allows us to define the research hypothesis that drive the paper. Section 3 describes the sample, the dependent/independent variables and their sources and the descriptive statistics. Section 4 is focused on research methodology, analysis and its results. Section 5 summarizes discussion on the results and finally, section 6 contains some concluding remarks and further research opportunities.

\section{Theoretical framework and research question}

From a theoretical point of view, market imperfections such as other reasons can justify public intervention. A particular type of public intervention is represented by financial supports that, in the European area, can specifically assume importance in terms of structural funds. They are aimed at increasing long-term growth in backwards areas supporting sustainability and, since 2008, the EU Commission encouraged using the funds to tackle the negative effects of the economic crisis. A huge amount of money is addressed to regional cohesion policy by the European Union that allocates to this aim about onethird of its budget for each programming period (Dall'Erba and Fang, 2017). Since their inception and until more recent times, European structural funds have been analyzed by scholars both in terms of their contribution to economic development (Nurse and Fulton, 2017) and in terms of reducing the economic gap between different regions (Czudec et al., 2019).

Entrepreneurship has a relevant role as a driver of worldwide economic and social growth considering that a large part of economic growth comes from entrepreneurial activities (Reynolds et al., 2000). In effect, entrepreneurship has enabled innovations that have positive impacts on quality of life, poverty and unemployment reduction, and opportunities for economic and social mobility (Yusuf, 2010). This mention of the importance of entrepreneurship for the economic development, allow us to put in evidence the issue of the effectiveness of European Union structural funds for entrepreneurship. These funds should face entrepreneurial vulnerability, especially in the start-up phase, reducing high failure rates. Starting and managing a business requires many different skills and resources. Entrepreneurs need the right mix of capital (ranging from human and social 
capital to physical capital) to succeed in a sustainable way. When unable to achieve the right combination of resources, entrepreneurs need external support to fill the gap. At the same time, public administration can be considered a key actor in supporting economic development (Calcagnini and Perugini, 2019) and, therefore, entrepreneurship. In particular, sub-national players (Dabrowsky, 2013), as local authorities, take on particular relevance in view of both their "proximity" to the economic fabric and their institutional role in governing the territory.

The impact of structural funds, in effect, is also studied in terms of effect on domestic policy actor, using the concept of Europeanization (Mendez et al., 2008; Ferry, 2007; Leonardi, 2005). Some authors find that structural funds can positively affect economic growth (e.g.: Garcia-Solanes \& Maria-Dolores, 2002; Lolos, 2009), while other authors do not show significant findings (Dall'erba and Le Gallo, 2008; Esposti and Bussoletti, 2008).

On the basis of the above literature premises, we aim to contribute to the scientific debate on the role of local authorities in the management of European structural funds intended for entrepreneurial development. In particular, this is done in order to verify the existence of a link between the European funds received and used by local authorities following the presentation of projects for economic development, and the entrepreneurial turnaround in the local area.

From this, the first research hypothesis arises:

HP1: "EU structural funds received by local governments have a positive impact on local entrepreneurship".

In order to be able to deepen the analysis, we also consider European structural funds intended for entrepreneurship and managed in the municipal area by entities other than local governments (Dabrowsky, 2013). Therefore, in formulating the second research hypothesis, even in the case of other users, we consider what the literature highlights about the positive impact of European funds on economic development (e.g. Faina et al., 2020). In fact, the potential success or failure of policies addressed to economic development is influenced by a plurality of interacting actors (Casula, 2020). Consequently, it is interesting to investigate the impact on economic development of the European structural funds when they are managed by players other than local governments.

Following, the second research hypothesis:

HP2: "EU structural funds received by other than local governments have a positive impact on local entrepreneurship”.

This will allow us a comparative analysis between the role of local governments and the role of other users of European structural funds aimed at entrepreneurial development. An additional element of novelty of the present work is represented by the fact that literature often utilizes the amount of structural funds which are programmed or committed (Aiello and Pupo, 2012), while we use the actual payments. 


\section{Sample, data and descriptive statistics}

The sample analyzed is composed by the 116 Italian provincial capitals for which we considered both the amounts of EU structural funds addressed to the municipal territory and the entrepreneurial turnaround (that is the difference between registered companies and deceased companies). Following the availability of data, we considered the 2007-2013 European funds programming cycle using the euros of European funds disbursed and allocated to those destinations most directly concerned the economic development that have a greater link to entrepreneurial turnaround. To this end, we took in consideration secondary data (OpenCoesione data set, an online open government iniziative on cohesion policies in Italy) and, in particular, we selected the amounts addressed to several sectors for the period 2007-2013 (see following Table I).

With reference to entrepreneurial turnaround, the period taken into account was 2014-2017, immediately following years of the 2007-2013 European funds programming cycle. This allowed the analysis to focus on the impact of EU funds on entrepreneurial turnaround. In the 2007-2013 cycle, the projects monitored were 952.931 for a public cost of $€ 95.9$ billion and payments of $€ 66.5$ billion. For the empirical analysis, the dependent variable was the entrepreneurial turnaround (turn_it) and the data source of this variable was the CCIAA (Chamber of Commerce, Industry, Crafts and Agriculture).

The independent variables were the amount of European funds gained by each municipality divided in the main sectors related to entrepreneurial development. We used the following sectors on the basis of the OpenCoesione classification: transport, research and innovation, employment, culture and tourism, company competitiveness, digital agenda and public administration reinforcement. In addition to the variables related to the aforementioned sectors, we also used the number of projects managed in the territory of the municipality as an independent variable. On the OpenCoesione website, many data were available: programmed resources and expenses, locations, thematic areas, programmers and actuators, implementation times and payments of individual projects.

The independent variables are illustrated in the following table:

Table 1 Independent variables definition

\begin{tabular}{|c|c|c|}
\hline Code & Variable & Source \\
\hline$t r a n s p_{i t}$ & Transport & OPENCOESIONE \\
\hline$r i_{i t}$ & Research and innovation & OPENCOESIONE \\
\hline$e m p_{i t}$ & Employment & OPENCOESIONE \\
\hline$c t_{i t}$ & Culture and Tourism & OPENCOESIONE \\
\hline$c c_{i t}$ & Companies competitiveness & OPENCOESIONE \\
\hline$d a_{i t}$ & Digital Agenda & OPENCOESIONE \\
\hline$p a r_{i t}$ & Public administration reinforcement & OPENCOESIONE \\
\hline$n p m_{i t}$ & Number of projects managed & OPENCOESIONE \\
\hline
\end{tabular}

With this sample, we created a balanced data panel (for local district $\mathrm{i}(\mathrm{i}=1, \ldots, \mathrm{n})$ at the time $\mathrm{t}(\mathrm{t}=2014, \ldots, 2017))$, which we used to estimate our models (Hsiao, 2003). Following, descriptive statistics are presented. First of all, the trend of the variable "turnaround", that was calculated as the mean per each year (2014-2017). We obtained the followings graphic: 
Graphic 1 Trend of the turnaround

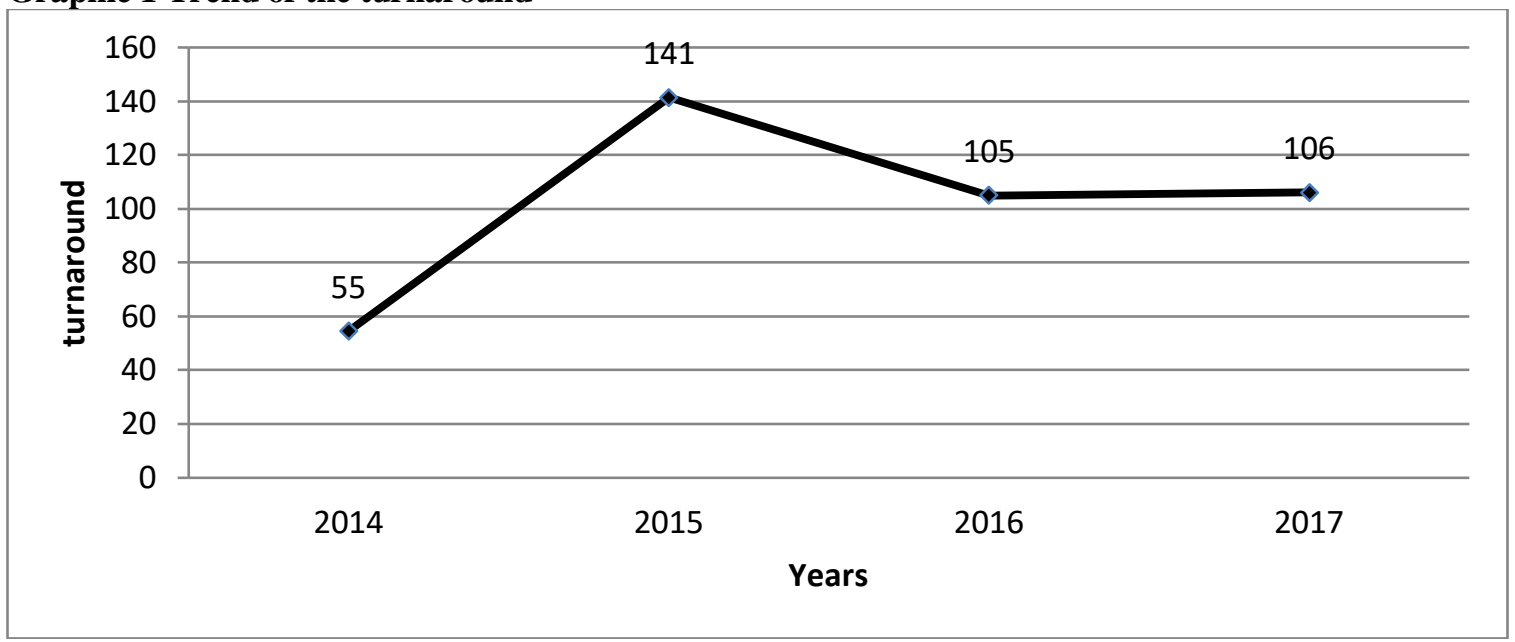

In the graphic I, the variable has an initial increasing trend, followed by a decline in 2016 and 2017. The followings table illustrates the most significant statistics of the dependent variable "turnaround".

Table 2 Statistics of number of turnarounds

\begin{tabular}{|c|c|c|c|c|c|}
\hline Year & Mean & Median & Standard Deviation & Max & Min \\
\hline 2014 & 55 & 2 & 342 & 2089 & -755 \\
\hline 2015 & 141 & 40 & 480 & 3288 & -72 \\
\hline 2016 & 105 & 48 & 425 & 2824 & -400 \\
\hline 2017 & 106 & 65 & 390 & 2397 & -862 \\
\hline
\end{tabular}

Source CCIAA - own elaborations

From what results we can imagine a high variability, than the average over the years. To verify this is sufficient to note that the standard deviation has the high values.

\section{Model, analysis and results}

The focus of this research is to analyse the turnaround of the local district. We suppose that this variable depend to:

- transport;

- research and innovation;

- employment;

- culture and tourism;

- companies competitiveness;

- digital agenda;

- public administration reinforcement;

- number of projects managed.

We developed a model, which the dependent variable "turnaround" (for local district $\mathrm{i}(\mathrm{i}=1, \ldots, \mathrm{n})$ at the time $\mathrm{t}(\mathrm{t}=2014, \ldots, 2017))$ and all previous variables like independent variables (for local district $\mathrm{i}$ at the time $\mathrm{t}$ ): 


$$
\operatorname{turn}_{i t}=k+\text { transp }_{i t}+r i_{i t}+e m p_{i t}+c t_{i t}+c c_{i t}+d a_{i t}+\operatorname{par}_{i t}+n p m_{i t}+u_{i t}
$$

Where:

$\operatorname{turn}_{i t}$ is turnaround; $\operatorname{transp}_{i t}$ is the transport; $r i_{i t}$ is the research and innovation; $e m p_{i t}$ is the employment;

$c t_{i t}$ is the culture and tourism; $c c_{i t}$ is the companies competitiveness; $d a_{i t}$ is the digital agenda;

par $_{i t}$ is the public administration reinforcement; $n p m_{i t}$ is the number of projects managed.

The methodology that we adopted to estimate the previous panel is the GLS (General Least Square) method. First of all, we can use this method because we haven't a lagged dependent variable. Then, our units of observation, local districts, differ in many significant ways (e.g. the size) and this is a common source of heteroscedasticity, which is a strong assumption that may not hold in applied problems like the one we are dealing with where the units of observation have an important spatial component. Some relatively recent contributions, such as Anselin and Lozano-Gracia (2008) or Baltagi et al. (2008), are typical examples of empirical applications that require the use of spatial heteroscedasticity and autocorrelation consistent estimators. Therefore, we can use to estimate the OLS (Ordinary Least Squares) method (Baulager-Coll et al, 2016). But we choose the GLS method because we have, also, random effect over the individuals (local districts). For this reason, we assume that the heterogeneity is distributed as a random variable with mean zero and variance $\sigma^{2}$. This last hypothesis takes, obviously, effect on the variancecovariance matrix of the error term that will not be diagonal. Therefore, to obtain estimate correct and efficient we must use the OLS method transformed, the GLS method, in which make a "almost" differentiation that is we subtracted to each observation to its mean over time.

In our model we inserted the temporal dummy variables $(\tau)$, through which we can capture the cyclical variations of the periods. Then:

$$
\begin{aligned}
\text { turn }_{i t}= & \beta_{0}+\tau_{t}+\beta_{1} \text { transp }_{i t}+\beta_{2} r i_{i t}+\beta_{3} e m p_{i t}+\beta_{4} c t_{i t}+\beta_{5} c c_{i t}+\beta_{6} d a_{i t} \\
& +\beta_{7} \text { par }_{i t}+\beta_{8} n p m_{i t}+u_{i t}
\end{aligned}
$$

At this point we proceeded with the estimation of this model. It should be emphasized that the data related to the independent variables (transp, ri, emp, ct, cc, da, par and npm) that we used in the regression were different. In fact, we estimated our model twice with two regressions that use, as independent variables, the values financed by the European Union related to projects won and implemented in the municipal area directly by the local government, on the one hand, and by implementers (both public and private) other than the local government, on the other hand. This allows us a comparison between the impact of the management of local governments and the impact of the management of other subjects. To do the regressions we used the econometric program STATA and we obtained the results contained in the following table: 
Table 3 Estimation

\begin{tabular}{|c|c|c|}
\hline Variable & $\begin{array}{l}\text { Municipality as actuator body } \\
\text { (Regression I) }\end{array}$ & $\begin{array}{c}\text { Another actuator body } \\
\text { (Regression II) }\end{array}$ \\
\hline Const & $\begin{array}{l}-18.28 \\
(33.70) \\
\end{array}$ & $\begin{array}{c}21.59 \\
(27.69) \\
\end{array}$ \\
\hline tau2014 & $\begin{array}{l}-51.32 \\
(32.17)\end{array}$ & $\begin{array}{l}-51.32 \\
(32.41) \\
\end{array}$ \\
\hline tau2015 & $\begin{array}{c}35.49 \\
(32.17)\end{array}$ & $\begin{array}{c}35.49 \\
(32.41)\end{array}$ \\
\hline tau2016 & $\begin{array}{c}-1.21 \\
(32.17)\end{array}$ & $\begin{array}{c}-1.21 \\
(32.41)\end{array}$ \\
\hline \multicolumn{3}{|l|}{ tau2017 } \\
\hline transp & $\begin{array}{c}-4.34 * * * \\
(1.25)\end{array}$ & $\begin{array}{l}-3.95 \\
(3.84)\end{array}$ \\
\hline ri & $\begin{array}{l}-7.64 \\
(7.42) \\
\end{array}$ & $\begin{array}{c}1.17 \\
(2.36) \\
\end{array}$ \\
\hline emp & $\begin{array}{c}31.60 * * * \\
(10.90) \\
\end{array}$ & $\begin{array}{c}-1.41^{* * *} \\
(3.89) \\
\end{array}$ \\
\hline $\mathrm{ct}$ & $\begin{array}{c}2.48 \\
(1.87)\end{array}$ & $\begin{array}{c}3.33^{* * *} \\
(2.72)\end{array}$ \\
\hline CC & $\begin{array}{c}134.00 * * * \\
(17.20)\end{array}$ & $\begin{array}{c}-6.41^{* * * *} \\
(1.49)\end{array}$ \\
\hline da & $\begin{array}{c}10.30 \\
(10.80)\end{array}$ & $\begin{array}{c}2.66 \\
(5.25) \\
\end{array}$ \\
\hline par & $\begin{array}{l}23.50^{*} \\
(15.10)\end{array}$ & $\begin{array}{l}2.02 * \\
(1.04)\end{array}$ \\
\hline npm & $\begin{array}{c}2397.48 * * * \\
(908.38)\end{array}$ & $\begin{array}{c}18.17 * * * \\
(14.03)\end{array}$ \\
\hline
\end{tabular}

Notes: standard errors (in bracket). *** denotes a level of significance at 1\%, ** denotes a level of significance at $5 \%$, * denotes a level of significance at $10 \%$.

\section{Discussion}

The first (second) regression evidences the relationship between European funds received and used by local governments (other actuator bodies) following the presentation of projects for economic development, on the one hand, and the entrepreneurial turnaround in the local area, on the other hand. As regard the first regression, some of the most statistically significant (p-value < 1\%) variables (projects on "employment", and "company competitiveness") have a positive and high association with "turnaround", whilst the "transport" variable (p-value $<1 \%$ ) is characterized by a weak (negative) relationship.

In the second regression, two of these variables (“employment”, and "company competitiveness") are statistically significant (p-value $<1 \%$ ), but having weak (and negative) association with local entrepreneurship. The transport variable is not significant. Moreover, in the second model we registered a positive and statistically significant association between projects on "culture and tourism" and local entrepreneurship, but the relationship is weak.

Both models are characterized by a strong positive association between the "number of projects managed" and the economic development, but the local governments role is more important than the one of the other actuators. It should be emphasized that in 
the first model, there is a high positive association between projects aimed at "public administration reinforcement" and "turnaround", but the association is less statistically significant (p-value $<10 \%$ ), than the previous independent variables in the same model. In the second model, projects on "public administration reinforcement" produce lower impact.

Finally, in both models, some independent variables ("research and innovation", and "digital agenda"), and all the control variables (temporal dummy ones) are not significant.

Findings indicated that the two hypotheses were confirmed, even if local governments produced higher positive impact, than other actors, in managing EU structural funds for local entrepreneurial development. Therefore, local authorities played a key role, in the four-year period analyzed (2014-2017). Particular mention should be given to “employment" and "companies' competitiveness" projects, together with initiatives for the "reinforcement of public administrations”.

\section{Conclusion}

The EU provides financial support to promote economic development and social inclusion through the so called structural funds (Zerbinati, 2012). Specifically, in this paper the entrepreneurial level (in terms of difference between registered companies and deceased companies in a fiscal year) is considered as an indicator of economic development (Namise et al. 2019). Development policies are affected by different factors and a plurality of actors (Casula, 2020). Among these, public administrations are key players in programming and implementing economic development policies (Calcagnini and Perugini, 2019). From this, the goal of this paper arises: it is to investigate both the role of local authorities in the management of European structural funds intended for entrepreneurial development (HP1) and the role of other users of European structural funds aimed at entrepreneurial development. Findings indicated that the two hypotheses were confirmed, even if local governments produced higher positive impact, than other actors, in managing EU structural funds for local entrepreneurial development.

As regards the role of public administrations on economic development, it should be underlined that "public administrations" represents one of the most important "pillars" of countries economic competitiveness, according to the World Economic Forum report on "global competitiveness index". The last report 2020 focuses the analysis on global priorities to overcome pandemic crisis, and emphasizes public sector key role on "reviving and transforming the enabling environment". More precisely, one of the global priorities for the next 1-2 years after pandemic crisis, is "improving the long-term thinking capacity within governments and mechanisms to deliver public services and supporting policy interventions digitally", whereas in the next 3-5 years it is paramount "ensuring public institutions embed strong governance principles and a long-term vision and building trust by serving their citizens”. Sub-national players (Dabrowsky, 2013), as local authorities, take on particular relevance in view of both their "proximity" to citizens and their institutional role in governing the territory. According to public management literature (Kickert, Klijn and Koppenjan, 1997; Agranoff, McGuire, 2003; Meneguzzo, Cepiku, 2008; Provan, Kenis, 2008; Bianchi, Trimigno, 2019), the attitude of local governments to create, manage or participate to policy or public service networks could be paramount for 
economic development. In fact, networking might give local governments the access to essential material (financial) and immaterial (know how) resources, which otherwise would be prevented to them. The presentation of EU structural funds projects could be a chance for local governments to create and manage network of private and public actors to improve economic development and produce positive impact on local entrepreneurship.

Considering the findings of this analysis in terms of positive impact of the EU structural funds managed by local governments on the entrepreneurial turnaround, we develop some policy making and managerial implications:

- policy-makers (especially considering that in this work reference is made to local governments) should maintain a constant relationship with the local business fabric in order to know and interpret its needs. In this way, policy-makers could define the most effective local development policies and intercept the most appropriate European funding opportunities for the defined policy goals;

- public management should develop adequate competences (internal or external to the municipality) for the drafting of economic development projects allowing access to European funding.

\section{References}

1. Agranoff R., McGuire M. (2003), "Inside the Matrix Integrating the Paradigms of Intergovermental and Network Management”, International Journal of Public Administration, vol. 26, n. 12, pp. $1401-1422$ https://doi.org/10.1081/PAD-120024403

2. Aiello F, Valeria Pupo V. (2012). "Structural funds and the economic divide in Italy", Journal of Policy Modeling, Vol. 34, pp. 403-418. https://doi.org/10.1016/j.jpolmod.2011.10.006

3. Arbolino R., Di Caro P., (2021). "Can the EU funds promote regional resilience at time of Covid19? Insights from the Great Recession”, Journal of Policy Modeling, Vol. 43(1), pp. 109-126. https://doi.org/10.1016/j.jpolmod.2020.10.001

4. $\quad$ Asandului, M., Lupu, D., Maha, L. G., \& Viorică, D. (2021). The asymmetric effects of fiscal policy on inflation and economic activity in post-communist European countries. Post-Communist Economies. https://doi.org/10.1080/14631377.2020.1867430

5. P. Bianchi, M. Trimigno (2019), "How does information system success come about in interorganizational networks of public services?”, Public Money \& Management, 41:3, pp. $236-245$ https://doi.org/10.1080/09540962.2019.1665361

6. Calcagnini G. and Perugini F. (2019). "Social capital and well-being in the Italian provinces", SocioEconomic Planning Sciences, 68, pp. 1-10. https://doi.org/10.1016/j.seps.2018.11.005

7. Casula, M. (2020). "Under which conditions is Cohesion Policy effective: proposing an Hirschmanian approach to EU structural funds”, Regional \& Federal Studies, DOI: 10.1080/13597566.2020.1713110.

8. C Czudec, A., Kata, R., \& Wosiek, M. (2019). "Reducing the development gaps between regions in Poland with the use of European Union funds”, Technological and Economic Development of Economy, Vol. 25(3), pp. 447-471.

9. Dabrowsky M. (2013). "Europeanizing Sub-national Governance: Partnership in the Implementation of European Union Structural Funds in Poland”, Regional Studies, Vol. 47(8), pp. 13631374 https://doi.org/10.1080/00343404.2011.628931

10. Dall'Erba S., Fang F. (2017). "Meta-analysis of the impact of European Union Structural Funds on regional growth”, Regional Studies, $\quad$ Vol. $\quad$ 51(6), $\quad$ pp. https://doi.org/10.1080/00343404.2015.1100285

11. Dall’Erba, S., \& Le Gallo, J. (2008). "Regional convergence and the impact of European structural funds over 1989-1999: A spatial econometric analysis”, Papers in Regional Science, Vol. 87(2), pp. 219244. https://doi.org/10.1111/j.1435-5957.2008.00184.x 
12. Esposti, R., \& Bussoletti, S. (2008). "Impact of Objective 1 funds on regional growth convergence in the EU: A panel-data approach", Regional Studies, Vol. 42(2), 159-173. https://doi.org/10.1080/00343400601142753

13. Faina A., Lopez-Rodriguez J., Montes-Solla P. (2020). "European Union regional policy and development in Spain: capital widening and productivity stagnation over 1989-2010”, Regional Studies, Vol. 54(1), pp. 106-119. https://doi.org/10.1080/00343404.2018.1542127

14. Ferry, M. (2007). "Comparing the influence of Structural Funds programmes on regional development approaches in Western Scotland and Silesia: adaptation or assimilation?", European Journal of Spatial Development, Vol. 23, pp. 1-28.

15. Garcia-Solanes, J., \& Maria-Dolores, R. (2002). "The impact of European Structural Funds on economic convergence in European countries and regions", in W. Meeusen, \& J. Villaverde (Eds.), Convergence issues in the European Union (pp. 334-358). Cheltenham, Glos: Edward Elgar.

16. Kickert W.J.M., Klijn E.H., Koppenjan J.F.M. (1997), "Managing Complex Networks”, Sage, London

17. Le Gallo J., Dall’Erba S., Guillain R., (2011). "The Local versus Global Dilemma of the Effects of Structural Funds", Growth and Change, Vol. 42(4), pp. 466-490. https://doi.org/10.1111/j.14682257.2011.00564.x

18. Leonardi, R. 2005. Cohesion Policy in the European Union: The Building of Europe, Basingstoke: Palgrave Macmillan.

19. Lolos, S. E. G. (2009). "The effects of EU structural fund on regional growth: Assessing the evidence from Greece, 1990-2005”, Economic Change and Restructuring, Vol. 42, pp. 211-228. https://doi.org/10.1007/s10644-009-9070-z

20. Mendez, C., Wishlade, F. and Yuill, D. (2008). "Made to measure: Europeanization, 'goodness of fit' and adaptation pressures in EU competition policy and regional aid", Journal of Comparative Policy Analysis, Vol. 10, pp. 279-290. https://doi.org/10.1080/13876980802231081

21. Meneguzzo M., Cepiku D. (2008), “Network pubblici: strategia, struttura e governance”, McGrawHill, Milano

22. Murzyn D. (2020). "Smart growth in less developed regions - the role of EU structural funds on the example of Poland”, Innovation: The European Journal of Social Science Research, 33:1, 96-113. https://doi.org/10.1080/13511610.2019.1611418

23. Namise E.Y., Zhuang J., Zhu F. 2019. "The relation between entrepreneurship and rural poverty alleviation in China”, Management Decision, 57(9), pp. 2593-2611. https://doi.org/10.1108/MD-11-20171153

24. Nurse A., Fulton M. (2017). "Delivering strategic economic development in a time of urban austerity: European Union structural funds and the English city regions", Local Economy: The Journal of the Local Economy Policy Unit, Vol. 32(3), pp. 164-182. https://doi.org/10.1177/0269094217704646

25. Provan K.G., P. Kenis (2008), "Modes of Network Governance: Structure, Management, and Effectiveness", Journal of Public Administration Research and Theory, Vol. 2, 229-252 https://doi.org/10.1093/jopart/mum015

26. Reynolds, P.D. (2000), "National panel study of US business startups: background and methodology”, Databases for the Study of Entrepreneurship, JAI Press, Greenwich, CT, pp. 153-227.

27. Yusuf, J.E. (2010). "Meeting entrepreneurs' support needs: are assistance programs effective?", Journal of Small Business and Enterprise Development, Vol. 17(2), pp. 294-307. https://doi.org/10.1108/14626001011041283

This article is an open access article distributed under the terms and conditions of the Commons Attribution - Non Commercial - No Derivatives 4.0 International License. 